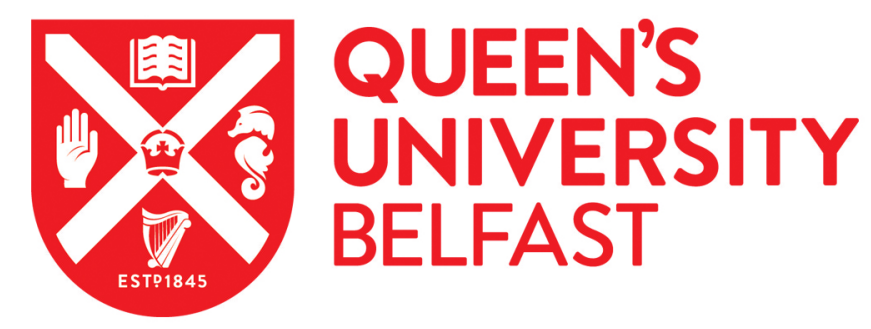

\title{
Perceptions of playing-related musculoskeletal disorders (PRMDs) in Irish traditional musicians. A focus group study
}

Wilson, I., Doherty, L., \& McKeown, L. (2012). Perceptions of playing-related musculoskeletal disorders (PRMDs) in Irish traditional musicians. A focus group study. Poster session presented at First Irish Multidisciplinary Conference on Scientific Research for Practice in Workplace Health, Safety and Wellbeing, Cork, Ireland.

Document Version:

Publisher's PDF, also known as Version of record

Queen's University Belfast - Research Portal:

Link to publication record in Queen's University Belfast Research Portal

\section{General rights}

Copyright for the publications made accessible via the Queen's University Belfast Research Portal is retained by the author(s) and / or other copyright owners and it is a condition of accessing these publications that users recognise and abide by the legal requirements associated with these rights.

Take down policy

The Research Portal is Queen's institutional repository that provides access to Queen's research output. Every effort has been made to ensure that content in the Research Portal does not infringe any person's rights, or applicable UK laws. If you discover content in the Research Portal that you believe breaches copyright or violates any law, please contact openaccess@qub.ac.uk. 


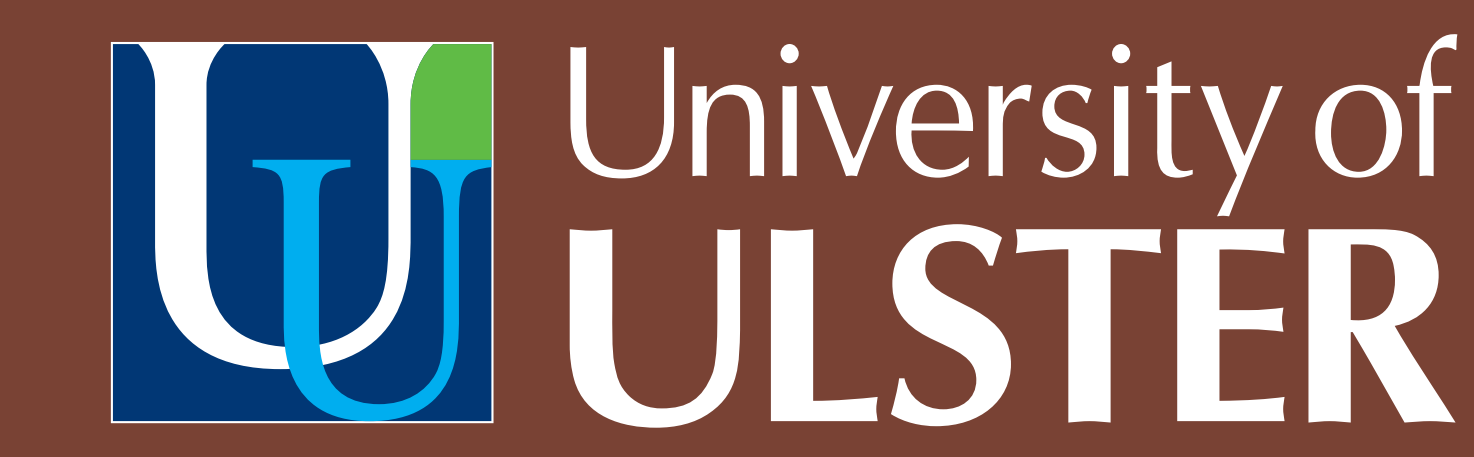

\section{sarts}

traditional arts

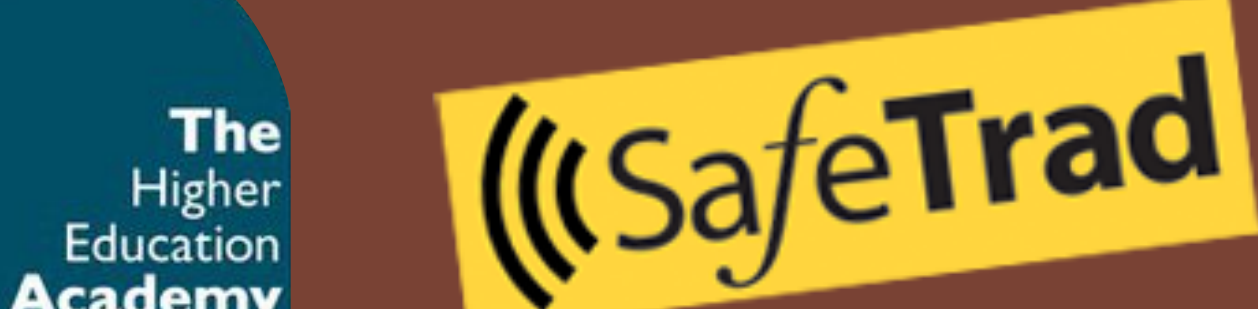

Playing-related musculoskeletal disorders in Irish traditional musicians: a focus group study

Iseult M Wilson, PhD., MSc., MCSP, MISCP ${ }^{1}$

Liz Doherty, PhD., BMus²

Laura McKeown, PhD., BSc(Hons)OT ${ }^{3}$

1: University of Ulster, Jordanstown and CHaRT (Centre for Health and Rehabilitation Technologies)

3: University of Ulster, Jordanstown

\section{Background}

Between $32 \%$ and $87 \%$ of musicians have playin related musculoskeletal problems (PRMDs)

- Most research has investigated PRMDs in classical

0 Conflict in the literature (classical $v$ folk):

There are similar patterns of injury when Previous work found differences between classical and folk [2]

- There has been very little research into Irish traditional musicians

- To date:

The pattern of injuries for classical musicians is different to those who play traditional music [2]

PRMDs are a significant problem and can cause neurological abnormalities [3]

PRMDs are a problem for traditional Irish musicians and there is a culture of silence and

This is the first study to explore the Irish traditional musician's perceptions of PRMDs

\section{Methods}

Focus groups $(n=4)$ in 2011 and 2012

Derry and Limerick

Ethical approval from the Research Ethics

Committee, University of Ulster

- Inclusion criteria:

Males or females aged 18 and above

Who taught or played Irish traditional music on

- Analysis

Interpretative approac

Independent analysis by two researchers

Same themes emerged

\section{Results}

\section{Participants: $(n=22)$}

Students

Teachers

University lectur

Nine engaged in more than one way (performing teaching, writing, music therapy)

From: Ireland $(n=16)$, Newfoundland $(n=$

$2)$, Sweden $(n=2)$, Shetland Islands $(n=1)$

Glasgow $(n=1)$

- Played: 8 to 40 years

Instruments played by participants

described..

PAIN

WEAKNESS

NUMBNESS

TINGLING

STIFFNESS

ACHING

CRAMPING

TENSION

TIREDNESS

TIGHTNESS

TWINGES

PINS and NEEDLES

PAIN

DISABILITY

IMPAIRED PLAYING CHANGED WAY OF PLAYING LACK OF CONTROL DIFFICULTY WITH DAILY ACTIVITIES FINANCIAL PROBLEMS STRESS DIFFICULTY SLEEPING
PRMDs: where they were...
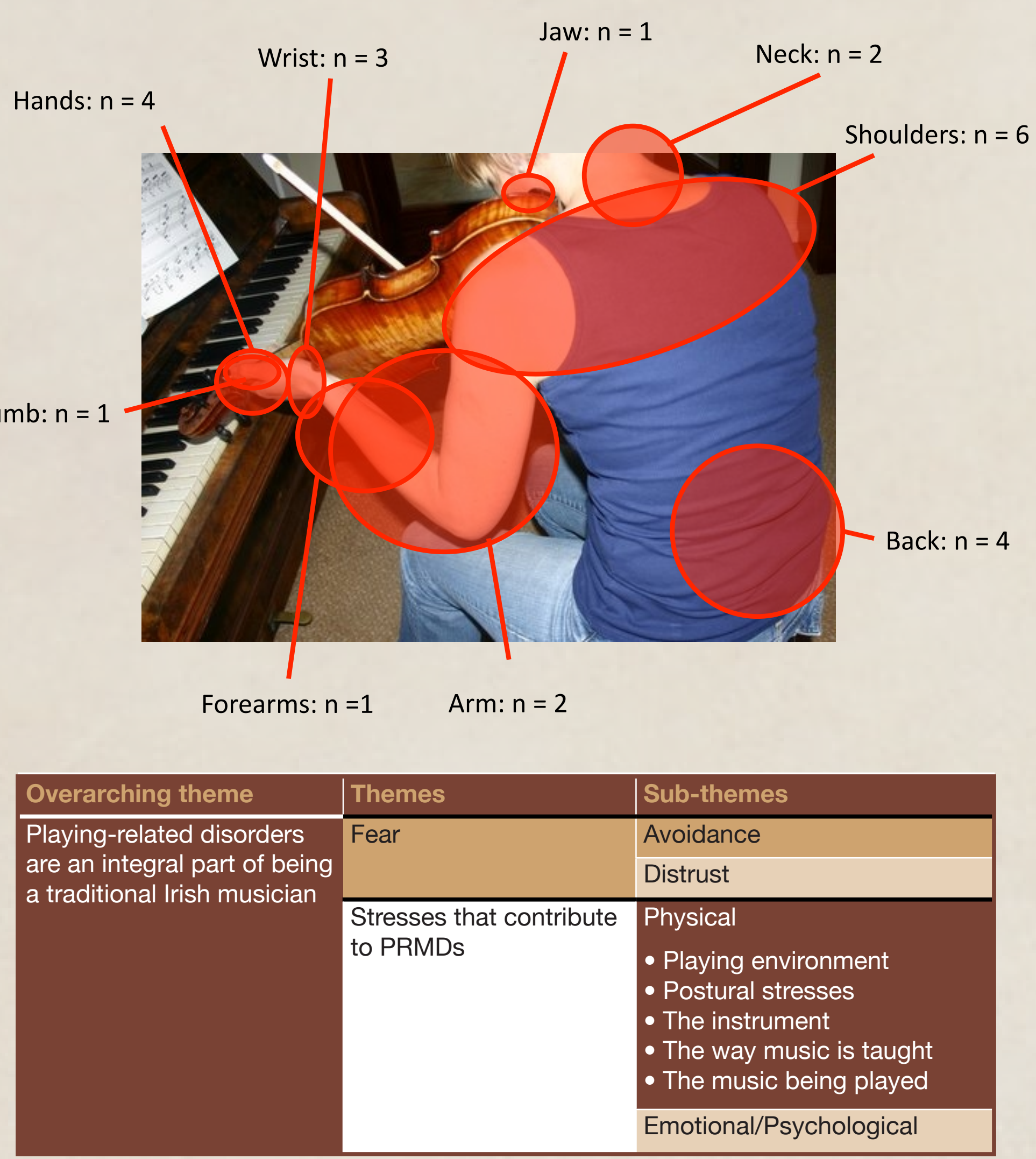

PRMDs are an integral part of being a traditional musician

- All participants believed there was a link between playing music and musculoskeletal problems

- Although problems are commonplace, traditional musicians do not treat PRMDs seriously

"Because it's music maybe it's not taken as seriously as a person who's into sports or even classical music" (Participant 7)

- Only 5 of the 22 participants did not currently have

- PRMDs were considered less important than the music and the whole musical experience

Fear

I think there is this massive fear of having to give it up, and maybe that's what it is, there's a block there where you know that you know you go to somebody that they might tell you to stop playing for 3 or 4 months and for people who are playing professionally a lot of time they can't afford to do that because they're ither teaching orplaying. And people who are doing it as a past-time a lot of the time don't want to give it up for some reason eith because I suppose a lot of them it's their outlet for enjoyment and I think that that could be something to do with it. I know it's just that they don't want to be actually told that they have to stop.'

(Participant 11)

Management of PRMDs in Irish traditional musicians

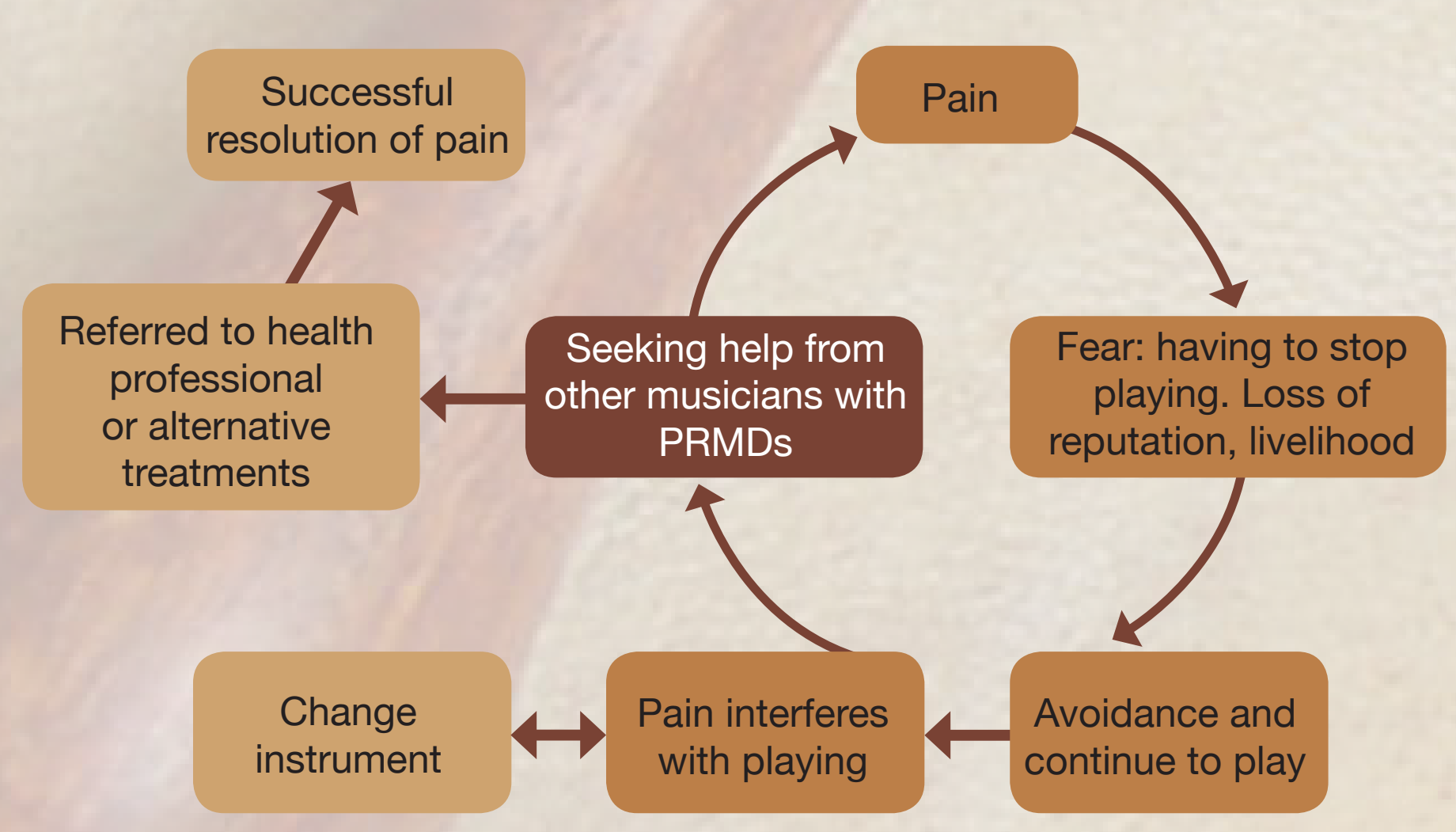

Fear: sub-theme avoidance

"I think people will look for help only when they are really in such a state that they can't play any more. Most people will go into denial "I am that is my experience - and will say then of course it gets worse. Finally when they can't do anything else, that is when they will go and seec help, when they have to either seete
Fear: sub-theme distrust of health professionals

- Several participants commented on the lack of unique needs of a musician, and especially, the

Health professionals will tell them to stop playing An intervention could do more harm than good

There are no clearly identified health professionals that specialise in PRMDs There is a lack of support for musicians with

Stresses contributing to PRMDs Physical

- Playing environment

Setting is not designed for performance (ofte pubs, bars)

Playing often happens at night and can last for

Although the setting may be unsuitable, there is a relion to them tolves (and thus away fraw music) by asking for more space or bringing the issue to everyone's attention

"You could be crammed into a corner of a pub and you do find that it is strenuous across the back" (Participant 11)

- Postural issues

Primarily "you'rejust sitting in unsuitable seating, weird positions and in and insufficient space (Participant 13)

Postural problems are recognised,

but not acted up

found the Alexander

technique very

useful

Identity of being

an Irish traditional

include warm-ups

and other exercise

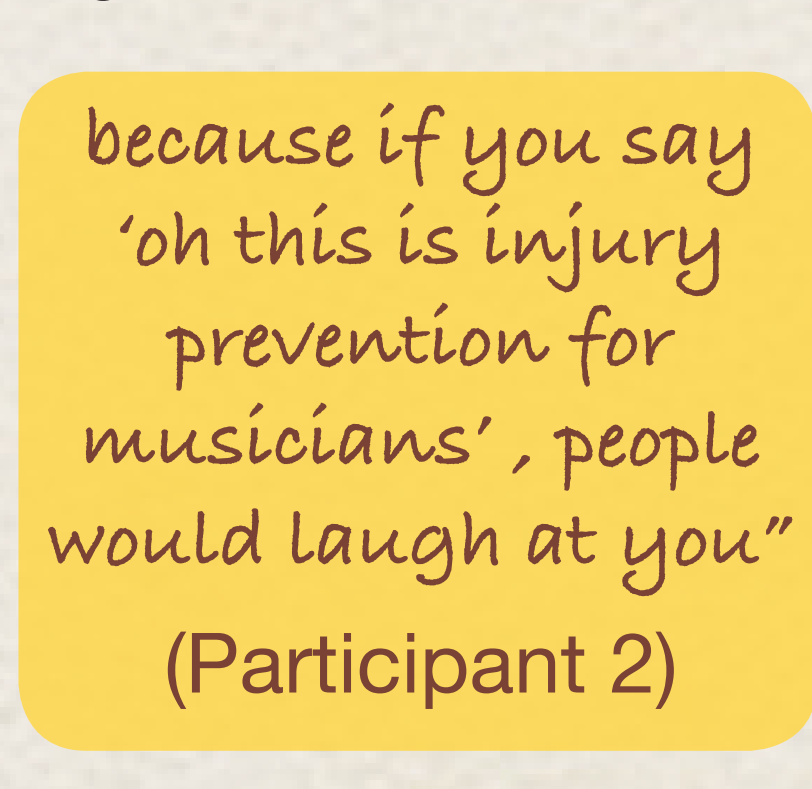

- The instrument

Quality and physical

Lesser quality and heavier instruments were more likely to cause PRMDs

Musicians alter their instruments to reduce

- The way music is taught

Traditional music is taught differently to classical

eatures that relate to PRMDs are: be up to 30 students) Lack of emphasis on posture when learning, and the difficulty of teaching this in a large class

Many musicians are self-taught

Little agreement on the 'right' or 'wrong' way to play an instrument

Pressure for students to leave the lesson having learned a tune (Classical musicians may work on one piece for weeks)

[the teacher just said] "put the fiddle

up there - there's your bow, work away" (Participant 8) help or stop playing."

Yeah I do [agree that speed is an issue]. ... the you are trying to is, the more pressure that in ..., I think you just automatically tense up try and get everything in there. Whereas if you go slower, it wouldn't be as hard'. Participants believe:

Health professionals do not understand the

Class sizes (classical is often 1:1, traditional can

Copying the teacher's posture and technique

Stresses contributing to PRMDs

Emotional/Psychological PRMDs if musician is:

- Nervous

- Anxious

Tense

- Stressed

Management includes trying to relax

\section{Discussion}

- In order to be successful, musicians must have: Physical and mental strength

Endurance

Manual dexterity

Technical precisio

Ability to play repetitively and rapidly, day after day, and year after year $[5,6]$

A successful musician and a successful athlete, will each have these same qualities.

Why is there such discrepancy in the management of their injuries?

- All participants either had one or more PRMD or

I Irish traditional musicians consider themselves, their music and their musical culture as very different to other musicians e.g. classical

- Despite being aware of problems such as seating etc., participating in music was more important than their pain and discomfort

WHY?

Because being a musician requires dedication, desire and discipline [6], and encompasses a sense of identity, a place in the musical community as
well as an income and way of life.

Take home messages

Musicians have a high prevalence of PRMDs

Irish traditional musicians identified specific issues and stresses within their culture that were

- Not all musicians are the same - there are diferent musical cillures as well as different

Health professionals must understand the musculoskeletal and performance demands of each musician, in order to provide help

\section{References}

BUCKLEY, T. and MANCHESTER, R., 2006. Overuse injuries in non-classical recreational instrumentalists. Medical Problems of Performing Artists, 21(2), pp.

GRANT, C.,S. and WILSON, I.M., 2006. PlayingSocity of Phys group pilot study, Chartered

O'CONNOR, G. and MCNAMARA, B., 2009. A review of neurological abnormalities associated with pp. 156-157.

DUNNE, B. and PETTIGREW, J., 2011. "It's not like I can just stop". The lived experience of pain in Irish traditional fiddlers., University of Limerick, Ireland. HEINAN, M., 2008. A review of the unique injuries sustained by musicians. Journal of the American
Academy of Physician Assistants, 21(4), pp. 45-50

DAWSON, W.,F., 2011. How and why musicians are different from non-musicians: A bibliographic review. 65-78.

\section{Acknowledgements}

Support for this research was received from The Arts Council/An Chomhairle Ealaín and The Higher Education Academy as part of the SafeTrad project (www.safetrad.com). 